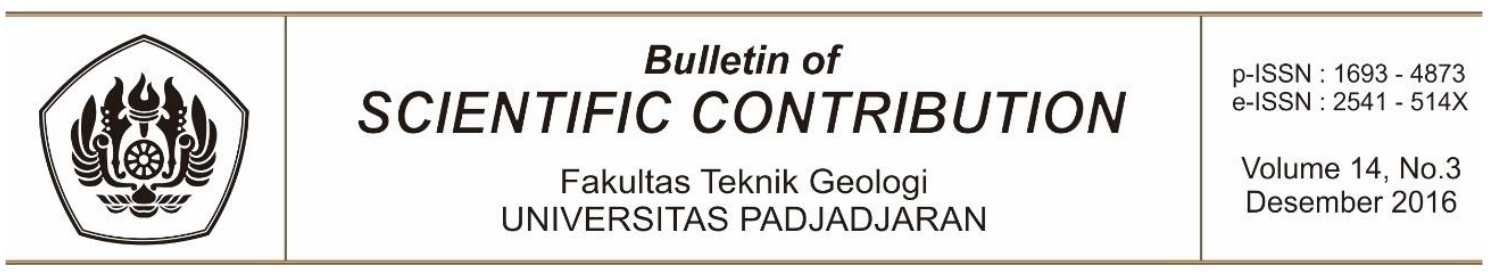

\title{
LINGKUNGAN PENGENDAPAN FORMASI KALIBENG PADA KALA MIOSEN AKHIR DI KABUPATEN DEMAK DAN KABUPATEN SEMARANG, JAWA TENGAH BERDASARKAN RASIO FORAMINIFERA PLANGTONIK DAN BENTONIK (RASIO P/B)
}

\author{
Lia Jurnaliah 1), Faizal Muhamadsyah 2), Nurisyam Barkah3) \\ ${ }^{1)}$ Laboratorium Paleontologi, Fakultas Teknik Geologi, Universitas Padjadjaran \\ 2)Laboratorium Sedimentologi, Fakultas Teknik Geologi, Universitas Padjadjaran \\ ${ }^{3)}$ Laboratorium Geologi Lingkungan \& Hidrogeologi, Fakultas Teknik Geologi, \\ Universitas Padjadjaran
}

\begin{abstract}
Research area is classified a Lower Kalibeng Formation. Its age is Lower Miocene. The total number of sediment samples is 29 samples that are carried out based on measured section with 10 meters interval. The whole samples are processed by hydrogen peroxide method. Foraminifers' quantitative analyses is conducted on each one gram of dry sample. Based on ratio $P / B$ value that range between $49.64 \%-$ $99.41 \%$, Late Miocene Kalibeng Formation is deposited on marine environment. The depositional process is beginning from neritic (outer neritic) - oceanic (upper bathyal-lower bathyal) - neritic (outer neritic) oceanic (upper bathyal - lower bathyal).
\end{abstract}

Keywords: Kalibeng Formation, planktonic and benthonic foraminifera, neritic, oceanic

\section{ABSTRAK}

Daerah penelitian merupakan Formasi Kalibeng bagian bawah berumur Miosen Akhir.. Pengambilan 29 sampel sedimen dilakukan secara sistematis berdasarkan penampang terukur dengan interval 10 meter. Seluruh sampel sedimen diproses dengn menggunakan metoda hydrogen peroksida. Analisis kuantitatif foraminifera dilakukan pada setiap 1 gram sampel kering berukuran $>120$ mesh. Berdasarkan hasil perhitungan rasio foraminifera plangtonik dan bentonik (rasio P/B) yang berkisar antara 49,64\% - 99,41\%, Formasi Sungaibeng Kala Miosen Akhir terendapkan pada lingkungan marin dimulai dari neritik (neritik luar) - oseanik (batial bawah-batial atas) - neritik (neritik luar) dan terakhir adalah oseanik (batial bawahbatial atas).

Kata Kunci: Formasi Kalibeng, foraminifera plangtonik dan bentonik, neritik, oseanik

\section{PENDAHULUAN}

Formasi Kalibeng berumur Miosen AkhirPliosen merupakan suatu formasi yang terdiri dari beberapa anggota dengan lingkungan marin yang bervariasi dari neritik sampai dengan batial (Sukardi dan Budhitrisna, 1992 dan Thanden, dkk, 1996). Penentuanvlingkungan pengendapan suatu daerah dapat dilakukan dengan menggunakan beberapa metode, salah satu diantaranya adalah dengan menggunakan mikrofosil.

Foraminifera adalah hewan uniseluler yang mempunyai kemampuan untuk membentuk cangkang dan hidup di laut. Kehidupan foraminifera sangat dipengaruhi oleh lingkungan sehingga mereka dapat digunakan sebagai indikator lingkungan. Berdasarkan cara hidupnya foraminifera dibagi menjadi 2 jenis yaitu foraminifera plangtonik dan foraminifera bentonik. Rasio kedua jenis foraminifera tersebut dapat digunakan untuk menentukan lingkungan (Grimsdale \& Morkhoven, 1955).

Menurut Boggs (2006) Klasifikasi lingkungan pengendapan purba adalah kontinental, marginal-marin dan marin. 


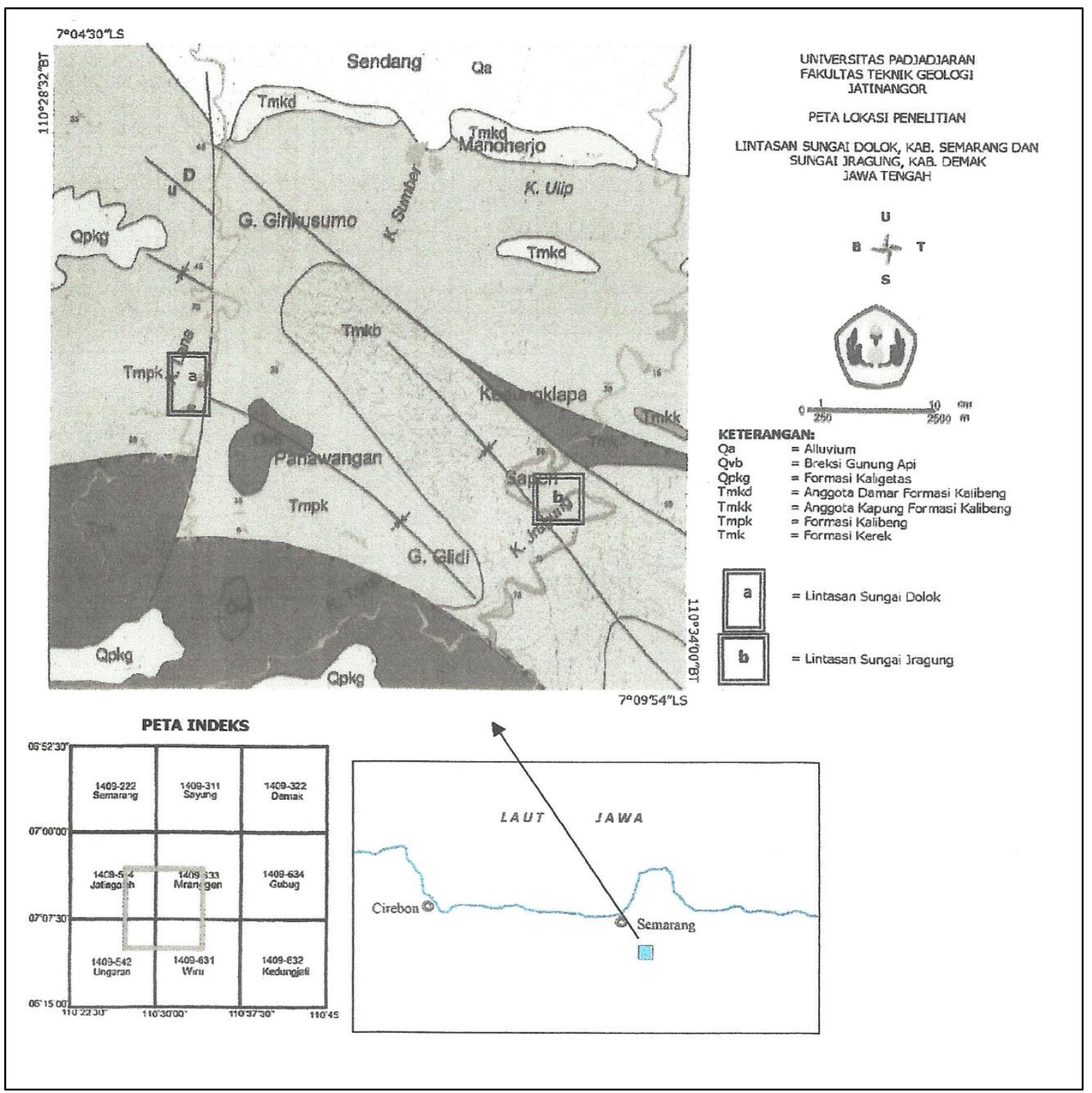

Gambar 1. Lokasi Penelitian (modifikasi Sukardi dan Budhitrisna, 1992 dan Thanden, dkk, 1996)

Selanjutnya Berggren dalam Haq \& Boersma (1998) membagi lingkungan marin menjadi 2 bagian yaitu neritik dan oseanik. Neritik terdiri dari neritik (litoral): neritik dalam, neritik tengah dan neritik luar. Sedangkan oseanik terdiri dari Batial (batial atas, batial tengah dan batial bawah), abyssal dan hadal. Interpretasi lingkungan pengendapan menggunakan rasio foraminifera plangtonik dan bentonik (rasio P/B) telah dilakukan oleh beberapa peneliti seperti Grimsdale \& Morkhoven (1955) dan Van Marle (1989).

Lokasi penelitian secara administratif terletak di Sungai Dolok, Kabupaten Semarang dan di Sungai Jragung, Kabupaten Demak, Jawa Tengah pada koordinat $110^{\circ} 28^{\prime} 32^{\prime \prime} \mathrm{BT}$ - $108^{\circ} 34^{\prime} 00^{\prime \prime} \mathrm{BT}$ dan 7०04'30"LS - 7०09"54"LS (Gambar 1).

Tujuan penelitian ini adalah untuk merekonstruksi lingkungan pengendapan Formasi Kalibeng pada Kala Miosen Akhir.

\section{BAHAN DAN METODA PENELITIAN}

Pengambilan 29 sampel sedimen pada dua lintasan yaitu Lintasan Sungai Jragung (16 sampel) dan Lintasan Sungai Dolok (13 sampel) dilakukan secara sistematis berdasarkan penampang terukur (measure section) dengan interval 10 meter.

Preparasi sampel sedimen menggunakan metode hidrogen peroksida. Analisis 
kuantitatif foraminifera dilakukan pada sampel kering berukuran > 120 mesh. Pada setiap 1 gram sampel kering dilakukan pemisahan dan penghitungan jumlah individu foraminifera plangtonik dan foraminifera bentonik (Foto 1 )

Rasio foraminifera plangtonik dan foraminifera bentonik dihitung dengan menggunakan rumus sebagai berikut:

Rasio $P / B=(P / P+B) \times 100 \%$

Keterangan: $P$ (jumlah individu foraminifera plangtonik) dan B (jumlah individu foraminifera bentonik) (Van Marle, 1989)

Nilai rasio $P / B$ kemudian diinterpretasikan menjadi lingkungan, yaitu: > 20\%: paparan dalam (neritik dalam), 10-60\%: paparan tengah (neritik tengah), 40-70\%: paparan luar (neritik luar), > 70\%: batial atas dan > 90\%: batial bawah (Murray, 1976 dan Boersma, 1983 dalam Valchev, 2003).

\section{HASIL DAN PEMBAHASAN}

Berdasarkan rekonstruksi data lapangan, posisi stratigrafi sampel sedimen dari lintasan Sungai Dolok berada di bawah sampel sedimen dari lintasan Sungai Jragung. Kedua lintasan tersebut berumur Miosen Akhir.

Litologi dari kedua Ilintasan sungai didominasi oleh lanau dengan sisipan batupasir dan batulempung.

Hasil penelitian menunjukkan lingkungan pengendapan daerah penelitian merupakan lingkungan marin dengan ditemukannya foraminifera plangtonik dan bentonik, kecuali pada sampel sedimen JRD0 dan JRD13. Ketidakhadiran foraminifera pada kedua sampel tersebut menunjukkan kemungkinan saat itu lingkungan marin menjadi lebih dalam yaitu abyssal atau hadal. Hanya beberapa jenis foraminifera saja yang dapat hidup pada lingkungang marin abyssal dan hadal

Nilai rasio $P / B$ dari kedua lintasan berkisar antara 49,46\% - 99,41\% dan bervariasi untuk setiap sampel sedimen. Nilai rasio P/B terendah terdapat pada
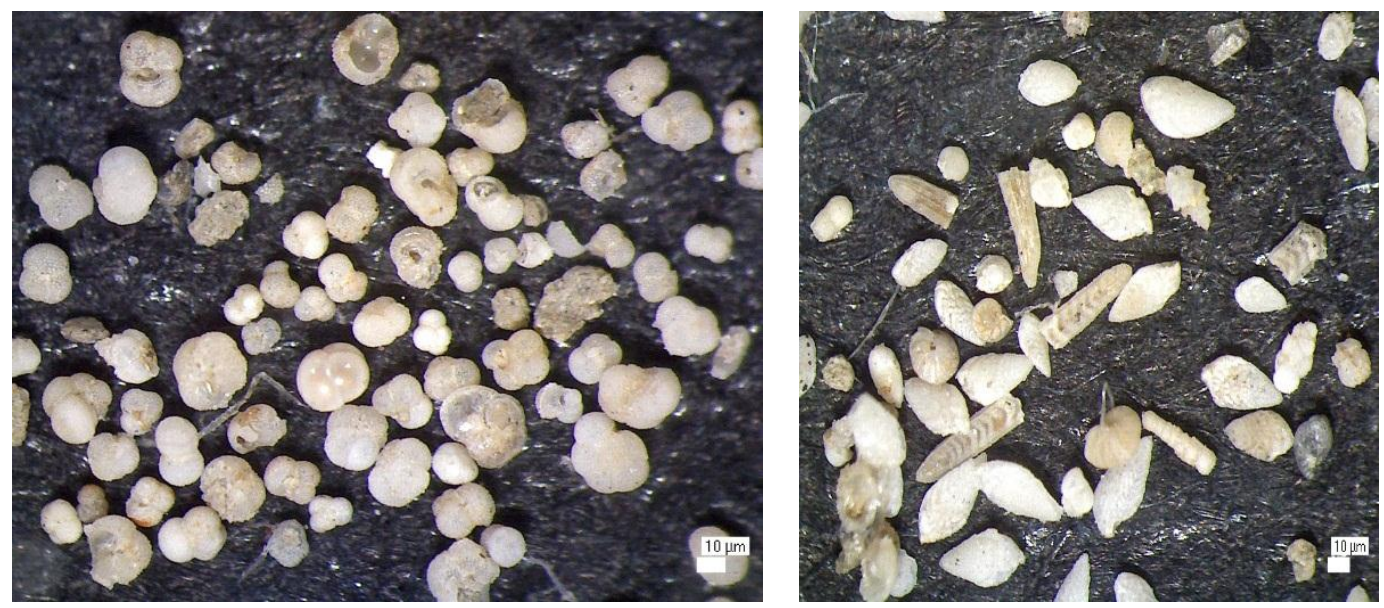

Foto 1. Kumpulan foraminifera plangtonik (kiri) dan kumpulan foraminifera bentonik (kanan) Pada sampel sedimen LRD 7

sampel LRD12 yaitu $49.46 \%$ artinya jumlah individu foraminifera bentonik dan foraminifera plangtonik hampir sama (Tabel 1 dan Tabel 2) Jumlah individu kedua jenis foraminifera yang hampir sama menunjukkan lingkungan marin menjadi lebih dangkal yaitu neritik luar.
Nilai tertinggi terdapat pada sampel JRD4 yaitu $99.41 \%$ artinya kandungan foraminifera pada sampel tersebut hampir semuanya adalah foraminifera plangtonik. 
Bulletin of Scientific Contribution, Volume 14, Nomor 3, Desember $2016: 233-238$

Tabel 1. Kelimpahan Individu Foraminifera Plangtonik dan Bentonik pada Lintasan Sungai Jragung

\begin{tabular}{|c|c|r|r|r|r|}
\hline NO & $\begin{array}{c}\text { KODE } \\
\text { SAMPEL }\end{array}$ & $\begin{array}{c}\text { JUMLAH } \\
\text { INDIVIDU } \\
\text { Foraminifera } \\
\text { plangtonik }\end{array}$ & $\begin{array}{c}\text { JUMLAH } \\
\text { INDIVIDU } \\
\text { Foraminifera } \\
\text { bentonik }\end{array}$ & $\begin{array}{c}\text { JUMLAH } \\
\text { TOTAL } \\
\text { INDIVIDU }\end{array}$ & $\begin{array}{c}\text { RASIO } \\
\text { P/B }\end{array}$ \\
\hline 1 & JRD0 & 0 & 0 & 0 & 0 \\
\hline 2 & JRD1 & 226 & 16 & 242 & 93,39 \\
\hline 3 & JRD2 & 16720 & 240 & 16960 & 98,58 \\
\hline 4 & JRD3 & 319 & 32 & 351 & 90,88 \\
\hline 5 & JRD4 & 85420 & 506 & 85926 & 99,41 \\
\hline 6 & JRD6 & 128 & 8 & 136 & 94,12 \\
\hline 7 & JRD7 & 6896 & 331 & 7227 & 95,42 \\
\hline 8 & JRD8 & 237 & 16 & 253 & 93,68 \\
\hline 9 & JRD9 & 11024 & 136 & 11160 & 98,78 \\
\hline 10 & JRD10 & 5000 & 160 & 5160 & 96,90 \\
\hline 11 & JRD11 & 58720 & 5472 & 64192 & 91,48 \\
\hline 12 & JRD12 & 1322 & 370 & 1692 & 78,13 \\
\hline 13 & JRD13 & 0 & 0 & 0 & 0 \\
\hline 14 & JRD14 & 308 & 24 & 332 & 92,77 \\
\hline 15 & JRD15 & 2812 & 731 & 3543 & 79,37 \\
\hline 16 & JRD16 & 125 & 35 & 160 & 78,13 \\
\hline
\end{tabular}

Tabel 2. Kelimpahan Individu Foraminifera Plangtonik dan Bentonik pada Lintasan Sungai Dolok

\begin{tabular}{|c|c|r|r|r|r|}
\hline NO & $\begin{array}{c}\text { KODE } \\
\text { SAMPEL }\end{array}$ & $\begin{array}{c}\text { JUMLAH } \\
\text { INDIVIDU } \\
\text { Foraminifera } \\
\text { plangtonik }\end{array}$ & $\begin{array}{c}\text { JUMLAH } \\
\text { INDIVIDU } \\
\text { Foraminifera } \\
\text { bentonik }\end{array}$ & $\begin{array}{c}\text { JUMLAH } \\
\text { TOTAL } \\
\text { INDIVIDU }\end{array}$ & $\begin{array}{c}\text { RASIO } \\
\text { P/B }\end{array}$ \\
\hline 1 & LRD1 & 314 & 128 & 442 & 71,04 \\
\hline 2 & LRD2 & 4432 & 1272 & 5704 & 77,70 \\
\hline 3 & LRD3 & 15836 & 5432 & 21268 & 74,46 \\
\hline 4 & LRD4 & 3916 & 496 & 4412 & 88,76 \\
\hline 5 & LRD5 & 19176 & 3264 & 22440 & 85,45 \\
\hline 6 & LRD6 & 31997 & 6987 & 38984 & 82,08 \\
\hline 7 & LRD7 & 5200 & 3232 & 8432 & 61,67 \\
\hline 8 & LRD8 & 3685 & 792 & 4477 & 82,31 \\
\hline 9 & LRD9 & 3408 & 720 & 4128 & 82,56 \\
\hline 10 & LRD10 & 10048 & 864 & 10912 & 92,08 \\
\hline 11 & LRD11 & 5632 & 768 & 6400 & 88,00 \\
\hline 12 & LRD12 & 736 & 752 & 1488 & 49,46 \\
\hline 13 & LRD13 & 704 & 448 & 1152 & 61,11 \\
\hline
\end{tabular}




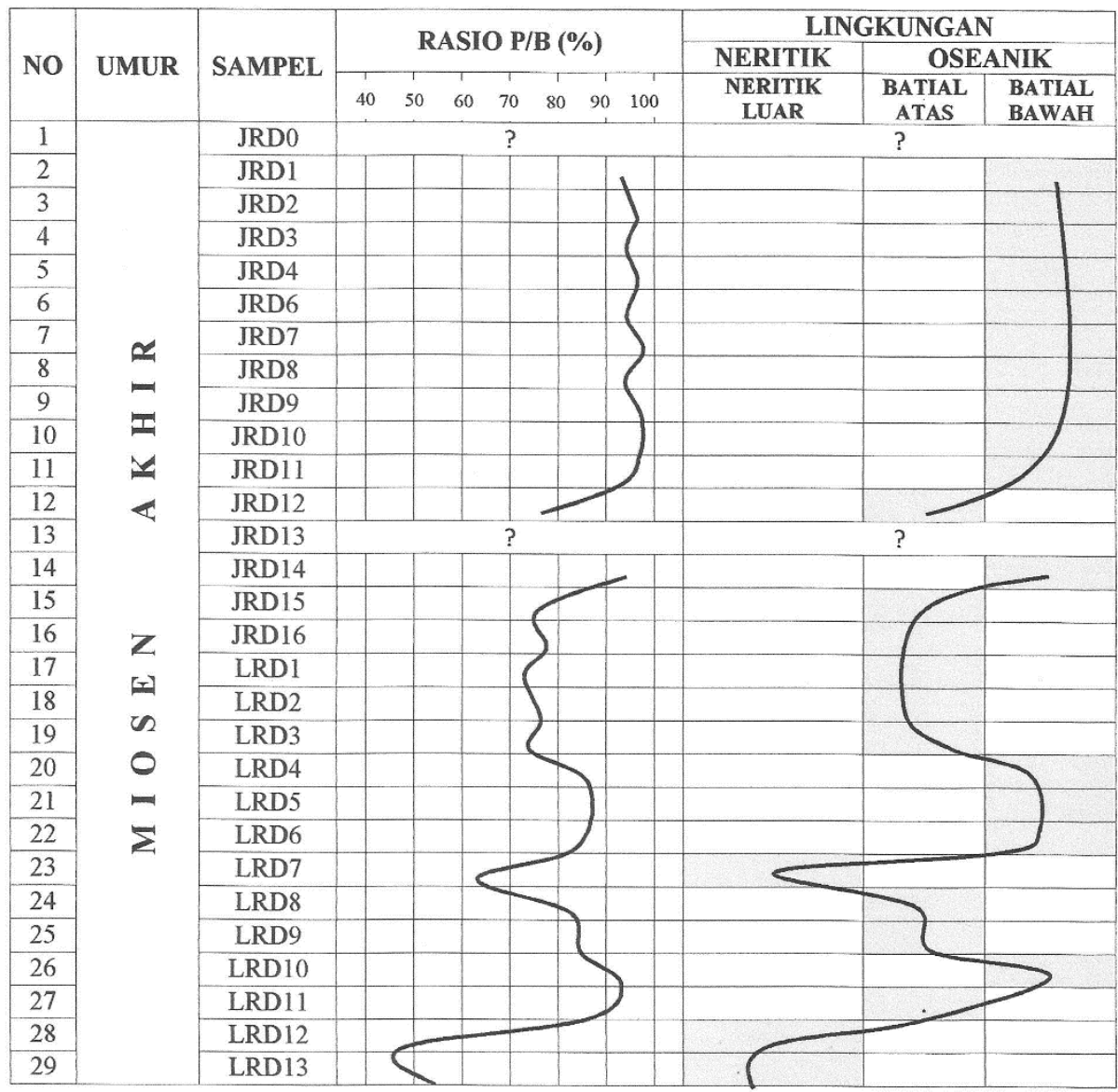

Gambar 2. Grafik perubahan nilai rasio P/B pada Formasi Kalibeng Kala Miosen Akhir menunjukkan adanya perubahan lingkungan marin: Neritik dan Oseanik

Jumlah individu foraminifera plangtonik yang sangat berlimpah menunjukkan lingkungan mrin pada kala itu menjadi lebih dalam yaitu oseanik (batial bawah) (Gambar 2)

Terjadinya perubahan nilai rasio $\mathrm{P} / \mathrm{B}$ pada setiap sampel sedimen menunjukkan adanya perubahan lingkungan. Pada Kala Miosen Akhir, daerah penelitian secara umum merupakan daerah dengan lingkungan marin yang terdiri dari Neritik dan Oseanik.

Pada Kala Miosen Akhir bagian Bawah yang diwakili oleh sampel sedimen dari lintasan Sungai Dolok terjadi beberapa perubahan lingkungan marin dimulai dari neritik yaitu neritik luar kemudian berubah menjadi oseanik yaitu batial atas-batial bawah. Setelah itu, lingkungan marin mendangkal menjadi neritik kembali yaitu neritik luar dan kemudian mendalam lagi menjadi oseanik yaitu batial atas-batial bawah. Memasuki Kala Miosen Akhir bagian Atas yang diwakili oleh sampel sedimen dari lintasan Sungai Jragung lingkungan marin menjadi lebih stabil yaitu berada pada lingkungan oseanik (batial atas batial bawah) (Gambar 2)

\section{KESIMPULAN}

Berdasarkan nilai rasio foraminifera plangtonik dan bentonik (rasio $P / B$ ), Formasi Kalibeng daerah penelitian diendapkan pada Kala Miosen Akhir dengan lingkungan marin. Di sepanjang waktu tersebut terjadi beberapa kali perubahan lingkungan marin yang diawali dengan neritik (neritik luar) Oseanik (batial atas - batial bawah) neritik (neritik luar) dan terakhir adalah oseanik (batial atas - batial bawah).

Perubahan lingkungan marin pada Kala Miosen Akhir dapat dipengaruhi oleh beberapa faktor diantaranya adalah perubahan muka air laut dan perubahan iklim. 


\section{DISKUSI}

Penelitian ini merupakan penelitian pendahuluan, perlu dilakukan penelitian lanjutan sehingga dapat diketahui penyebab terjadinya perubahan lingkungan marin di daerah penelitian

\section{UCAPAN TERIMA KASIH}

Ucapan terima kasih kami haturkan kepada pimpinan Fakultas Teknik Geologi, Kepala Laboratorium Paleontologi dan Universitas Padjadjaran yang telah memberikan kesempatan kepada kami untuk melaksanakan penelitian dengan dana Hibah

Pengembangan Kapasitas Riset Dosen (HPKRD) Tahun 2016.

\section{DAFTAR PUSTAKA}

Boggs, Jr. S. 2006. Principles of Sedimentology and Stratigraphy. Pearson Education, Inc. Pearson Prentice Hall. Upper Saddle River, NJ 07458.

Grimsdale, F.F \& Morkhoven, F.P.M.C. 1955. The Ratio Between Pelagic and Benthonic Foraminifera as means of Estimating Depth of Deposition of Sedimentary Rocks. Proc. Fourth World Petrol.
Congress, Rome, Sec. 1/D. Rep.4. pp 473-491.

Haq, B.U. dan Boersma, A., 1998. Introduction to Marine Micropaleontology. Elsevier Science (Singapore) Pte Ltd.

Sukardi dan Budhitrisna, T., 1992. Peta Geologi Lembar Salatiga, Jawa. Pusat Penelitian dan Pengembangan Geologi, Bandung.

Thanden, RE., Sumadirdja, H., Richards, PW., Amin, TC., 1996. Peta Geologi Lembar Magelang dan Semarang, Jawa. Skala 1 : 100.000. Pusat Survey Geologi, Bandung, Indonesia.

Valchev, B., 2003. On The Potential of Small Benthic Foraminiferal as Paleoecology indicators: Recent Advances. 50 Years University of Mining and geology "St. Ivan Rilski". Annual. Vol. 46, Part I, Geology

Van Marle, L.J. 1989. Benthic Foraminifera From The Banda Arc Region, Indonesia, and Their Paleobathymetric Significance For Geologic Interpretations of The Late Cenozoic Sedimentary Record. Free University Press, Amsterdam. 